\title{
The Effect of Duration of Antipsychotics Medicine Use Toward The Salivary Flow Rate of Schizophrenics In Special Hospital of South Sulawesi Province
}

\author{
Nursyamsi Djamaluddin ${ }^{1}$, Ayub Irmadani Anwar ${ }^{2}$, Rini Pratiwi Sadad ${ }^{3}$, Fikha Dwisari \\ R.A.P ${ }^{4}$, Dwi Putri Wulansari ${ }^{5}$ \\ \{ nursyamsi4874@gmail.com ${ }^{1}$, ayubanwar_mks@yahoo.com ${ }^{2}$, rinipratiwi.sadad@gmail.com ${ }^{3}$, \\ fikhadwisari@yahoo.com ${ }^{4}$, dwiputriwulansari51@gmail.com $\left.{ }^{5}\right\}$ \\ Dental Public Health Department, Faculty of Dentistry, Hasanuddin University, Makassar, Indonesia \\ Dental and Maxillofacial Radiology Department, Faculty of Dentistry, Hasanuddin University, \\ Makassar, Indonesia ${ }^{1-5}$
}

\begin{abstract}
Oral health is a part of general health that should not be separated from mental health. Oral health research in psychiatric patients shows that mental disorders and the use of such drug therapy as antipsychotic drugs can escalate the prevalence and severity of oral diseases. The objective of this study to examine the effect of antipsychotic medication by using duration toward the salivary flow rate of schizophrenics in the Special Hospital of South Sulawesi Province. This research is an analytical observation with Cross-Sectional study design. The 74 sample patients was obtained from nonprobability sampling method. The study was conducted at Dadi Special Hospital of South Sulawesi. The obtained data were analyzed by linear regression test and processed using the SPSS application 23.0 version (SPSS Inc., Chicago, IL, USA). The duration of drug use had a significant impact on the salivary flow rate of schizophrenics $(p<0.05)$. Based on the $F$ test, the value of the $F$ statistic was obtained 8.851 with the number of significanceprobability 0.004 , and the coefficient value of determination is 0.109 . There is a duration effect of antipsychotic drug use on the decreasing of the salivary flow rate of schizophrenics significantly as the side effect of antipsychotic drug use.
\end{abstract}

Keywords: Please list your keywords in this section.

\section{Introduction}

According to the World Health Organization (WHO) data about world mental health in 2016, there are about 21 million people suffered schizophrenia. Meanwhile, the prevalence of severe mental disorders in Indonesia is 1.7 per 1000 or about 400,000 people. Schizophrenia is one of the most severe mental disorders, in which its development is to be a chronic disease. Commonly, Schizophrenia appears in the early 20 age, and it inflicts a serious impact, particularly the sufferers could not complete their study or have a decent job, so that the disease causes enormous drawback as well as need high hospital cost service, sustainable treatment, rehabilitation and support from family and environment [1].

Schizophrenia can be defined as a psychotic disorder signed by the presence of positive symptoms of delusions and hallucinations as well as negative symptoms of flat effects, apathetic, and anhedonia. Schizophrenics also experience bother in interaction with others, like less eye contact, delayed response, unsuitable face expression, decreasing spontaneity, and the lack of ability to recognize others emotion [2]. 
Oral health is the part of general health that should not be separated from mental health. Several studies in the oral health of psychiatric patients in various countries denote that mental disorders and the use of such drug therapies as antipsychotic drugs can cause the improvement of prevalence and severity of oral diseases [3], [4].

The antipsychotic drug commonly used for schizophrenics works by blocking dopamine nerve receptors D2 and reducing the intensity of psychotic hallucinations [5]. The first generation antipsychotic drugs, like chlorpromazine and haloperidol, have side effects in the form of extrapyramidal syndromes which cause reflex in motor function unconsciously, so that the patients are difficult for maintaining their oral health sufficiently, which cause disruption such as xerostomia and side effects on the other neuroendocrine to be able to inflict menstrual disorders [4], [6].

The diminishing of the salivary flow rate of schizophrenics can reduce the quality of life, upgrading the plaque and forming the calculus, which might continuously improve dental caries, gingivitis, and periodontitis [6]. A research conducted by So-Jung Mun et al found that $68.9 \%$ of total schizophrenic patients studied experienced dysfunctional saliva. Drugs consumed by schizophrenics reduce significantly the rate of salivary stimulation flow so that patients have difficulty chewing and swallowing food due to xerostomia and low salivary secretions [7].

The fact found in Makassar City showed the high rate of schizophrenia occurrences based on RISKESDAS 2013, in which Makassar was included in the high five of the prevalence of schizophrenia cases in Indonesia, besides Yogyakarta, Aceh, Bali, and West Java1. However, there has been no study regarding oral health status, including salivary flow rate in schizophrenic patients. Based on this fact, researchers conducted a study to examine the effect of duration of antipsychotics medicine use toward the salivary flow rate of people with schizophrenia in the Special Hospital of South Sulawesi province. Other paragraphs are indented.

\section{Method}

This research is an analytical observation with Cross-Sectional study design using nonprobability sampling method with 74 sample patients. The study was conducted at the Dadi Regional Special Hospital of South Sulawesi, Makassar City, on 19-23 April 2017. The first paragraph after a heading is not indented.

The sample of the study was inpatients who were diagnosed schizophrenics undergoing antipsychotic drug therapy in Special Hospital of South Sulawesi with inclusion criteria. That is, aged more than 20 years old, cooperative patients, being present at the research period, not using prosthodontic and orthodontics tools, not consuming something, brushing teeth and smoking for 1 hour before the saliva was taken. Those who are not willing to participate in the study, had diabetes mellitus record, rheumatoid arthritis and Sjogren's syndrome which can affect oral conditions, and sufferer with an oral hypoglycemic drug use record, ACE inhibitors and opioids as well as those are undergoing radiotherapy, chemotherapy and/or having undergone salivary gland surgery, were exclusive criteria in this research.

The data obtained were processed by using the SPSS application 23.0 version (SPSS Inc., Chicago, IL, USA), presented in tables and elaborations and analyzed by linear regression test. 


\section{Result}

Table 1 illustrates the distribution of the sample by age and sex with total sample of 74 patients.

Table 1. Distribution of research sample characteristics first paragraph after a heading is not indented.

\begin{tabular}{lccc}
\multicolumn{1}{c}{ Sample characteristic } & n & \% & Mean \pm SD \\
\hline Sex & & & \\
$\quad$ Male & 34 & 45.9 & $36.30 \pm 7.37$ \\
$\quad$ Female & 40 & 54.1 & $33.11 \pm 4.95$ \\
$\begin{array}{l}\text { Age (years) } \\
\quad 21-40\end{array}$ & 50 & 67.6 & $46.22 \pm 4.05$ \\
$\quad 41-60$ & 24 & 32.4 & $20.39 \pm 33.06$ \\
$\begin{array}{l}\text { Duration of drugs use (months) } \\
\quad \leq 12\end{array}$ & 51 & 68.9 & $4.82 \pm 3.01$ \\
$\quad>12$ & 23 & 31.1 & $54.91 \pm 42.42$ \\
$\begin{array}{l}\text { Unstimulated Salivary flow rate } \\
\text { (ml/minute) }\end{array}$ & & & $0.30 \pm 0.15$ \\
Total & 74 & 100 & \\
\hline
\end{tabular}

Table 2 depicts the salivary flow rates based on use duration of antipsychotic drugs $(\leq 12$ months or $>12$ months). Samples with antipsychotic drug use duration $>12$ months showed a lower salivary flow rate with $0.24 \pm 0.13 \mathrm{ml} / \mathrm{min}$ if it was compared with samples which used drugs $\leq 12$ months $0.32 \pm 0.15 \mathrm{ml} / \mathrm{min}$.

Table 2. Saliva flow rate based on the duration of drug use

\begin{tabular}{cccccc}
\hline \multirow{2}{*}{ Duration of drug use } & \multicolumn{5}{c}{ Salivary flow rate (ml/minute) } \\
\cline { 2 - 6 } & $\mathbf{n}$ & $\boldsymbol{\%}$ & Min & Max & Mean \pm SD \\
\hline$\leq 12$ months & 51 & 68.9 & 0.08 & 0.80 & $0.32 \pm 0.15$ \\
$>12$ months & 23 & 31.1 & 0.06 & 0.58 & $31.1 \pm 0.13$ \\
\hline Total & 74 & 100 & 0.06 & 0.80 & $0.30 \pm 0.15$ \\
\hline
\end{tabular}

Table 3 denotes that schizophrenia patients having odd/abnormal salivary flow rates with $62.7 \%$ for $\leq 12$ months use duration, and $82.6 \%$ samples are experiencing odd/abnormal salivary flow rates for $>12$ months range. $\mathrm{P}$ value $>0,05$ indicates that there is no significant relationship between the duration of antipsychotic drug use and salivary flow rates of schizophrenic patients.

Table 3. The relationship between duration of antipsychotic drug use and the salivary flow rate of schizophrenic patients

\begin{tabular}{lll}
\hline Duration of drug use & Salivary flow rate $(\mathrm{ml} / \mathrm{minute})$ & $P$ \\
\hline
\end{tabular}




\begin{tabular}{|c|c|c|c|c|c|c|c|}
\hline & \multirow[t]{2}{*}{$\mathrm{n}$} & \multirow[t]{2}{*}{$\%$} & \multicolumn{2}{|c|}{ Normal } & \multicolumn{2}{|c|}{ Abnormal } & \\
\hline & & & $\mathbf{n}$ & $\%$ & $\mathbf{n}$ & $\%$ & \\
\hline$\leq 12$ months & 51 & 68.9 & 19 & 37.3 & 32 & 62.7 & 0073 \\
\hline$>12$ months & 23 & 31.1 & 4 & 17.4 & 19 & 82.6 & \\
\hline
\end{tabular}

Chi Square Test, $p<0.05$ significance

Table 4 illustrates that the duration of drug use had a significant effect on salivary flow rate in schizophrenic patients with $\mathrm{p}<0.05$. Meanwhile, for the effect of drug use on salivary flow rate, it was found $b=-0.002$, which showed a negative correlation and very weak relationship.

Based on $\mathrm{F}$ test, the value of $\mathrm{F}$ statistic was obtained 8.851 with the number of significance-probability 0.004 , so that it can be concluded that regression model can be used to predict the effect of antipsychotic drug use duration toward salivary flow rate. The coefficient of determination in this research is 0.109 . This means that the variable of salivary flow rate is influenced by the duration of antipsychotic drug use, 10.9 percent.

Table 4. The effect of antipsychotic drugs use duration toward the salivary flow rate on schizophrenics

\begin{tabular}{cccccc}
\hline Variable & B & SEB & Sig & F & $\mathbf{R}^{2}$ \\
\hline $\begin{array}{c}\text { The duration of } \\
\text { antipsychotic drug use }\end{array}$ & -0.002 & 0.001 & 0.004 & $\begin{array}{c}8,851 \\
(0.004)\end{array}$ & 0.109 \\
\hline
\end{tabular}

Description: Linear regression test; B (the correlation between the independent variable and dependent variable), SEB (standard error correlation), Sig (significance value of the independent variable to dependent), F (significance value of independent variable influencing simultaneously to a dependent variable), R2 (coefficient of determination).।

\section{Discussion}

This study found that there are more schizophrenia patients aged ranging from 21 to 40 years old (50 patients), compared with those aged 41-60 years old (24 patients). Such matter is corresponding with the reference which states that schizophrenia often occurs in the range of 15-44 years because these ages are the self character development periods and one's productive period of person [8]

Schizophrenia is one of the most common mental disorders that cause salivary secretion of salivary pharmacotherapy in the use of antipsychotic drugs. In case of disruption on salivary secretions, this will inflict a serious impact on the health status of patients, especially oral health [7].

The measurement of salivary flow rate in this research was conducted without stimulation, to collect salivary flow rate easily and it can describe conditions in the oral cavity, as well as with one's body condition [9]. 
Some oral health studies of psychiatric patients found that mental disorders and psychotropic drugs can result in salivary glandular hypertension and xerostomia as the side effects of drug use, therefore, this can improve the prevalence and severity of the dental disease. The secretion of the salivary glands is commonly affected by autonomic nerve control. Such secretion depends on some modulus that can occur in AMP cycles or calciumdependent pathways. The use of antipsychotic drugs can affect the autonomic nerves so that it influences the sympathetic nerve work to reduce salivary flow rate. 6 This study manages to find that people with schizophrenia in use duration $>12$ months had a less salivary flow rate than normal condition, and it is lower when such condition is compared with the rate of salivary flow on patients consuming antipsychotic drugs $\leq 12$ months. This is parallel with a longitudinal study conducted by Navazesh et al. in Krunic. They found that patients who took the drug for a long time significantly had a lower salivary flow rate with or without stimulation compared with patients who took the drug within one year [7].

The findings of this study also showed a significant effect between salivary flow rate and the duration of antipsychotic drug use. An identical thing was also found by Handelman et al. in Krunic in his study that found the rate of salivary flow of stimulation decreased following the increasing amount and time of xerogenic drugs use [7].

The effect of use duration of the drug to salivary flow rate was also influenced because the research samples used more polypharmacy drugs than antipsychotic monotherapy according to a study by Hashimoto $\mathrm{Y}$ et al. They found dry mouth condition as a distinct side effect of the antipsychotic drug use between the use of monotherapy drugs and polypharmacy. Patients with the use of polypharmacy drugs were proved to have lower salivary flow rates compared with salivary flow rates in patients taking antipsychotic drug monotherapy.16 However, the effect found in this study was very weak. This occurs because there are other factors that affect salivary flow rates, such as a combination of antipsychotic drugs. In this study, many research samples used the first and second antipsychotic drug combinations. Class II (atypical) antipsychotic drugs such as clozapine, risperidone and olanzapine do not only work on dopamine D2 receptors, so that side effects inflicted are lower compared with typical class I (chlorpromazine and risperidine) antipsychotic drugs9. Other influencing factors are the use of Clozapine that can increase saliva flow rate (hypersalivation). Clozapine has a more influential effect on D4 receptors than D2 receptors. Several studies have reported the incidence of hypersalivation in clozapine users by $30-80 \%$. The induced hyperactivation of this clozapine may decrease over time, can also become more severe and persistent, and cause night-time disruption.

Schizophrenia patients that experience such negative symptoms as apathetic affecting habits and reducing the desire and motivation of patients in maintaining their oral cavity health status. The cognitive implications of schizophrenia, such as weak memory and lack of attention, diminish their ability to recognize and overcome oral health problems.18 Psychiatrists and mental health practitioners supposed to take more time and attempt to obtain a patient's dental record, explaining the side effects of antipsychotic drugs such as mouth dry and provide saliva replacement and/or stimulants, perform dental health evaluation, consultation and follow-up if needed, and provide education to patients on how to maintain their dental health such as brushing, using dental floss, anti-caries agents (fluoride toothpaste) and chlorhexidine mouthwash.19 Other paragraphs are indented.

\section{Conclusion}


Based on the result of this research, it is proved that there is an effect of salivary flow rate to the reduction of schizophrenic patients due to the duration of antipsychotic drugs use. For the next research, we can use a cotton swab technique to take the saliva for the more accurate measurement result of salivary flow rate. Also, it is necessary to pay attention to the detail of dosage, drug type, and daily amount of antipsychotic drug and its effect on the salivary flow rate of schizophrenic patients.

\section{Reference}

[1] Departemen Kesehatan Light hope for schizophrenia.:warn peringatan hair kesehatan jiwa (2014)

[2] Myra, Thioritz W, Tanra AJ.: Pengaruh olahraga jogging sebagai tambahan terapi terhadap perbaikan gejala klinis penderita skizofrenia. JST Kesehatan Vol.5.pp.163-4. (2015)

[3] Djordjevic V, Jovanovic M, Milicic B, Stefanovic V, Dejanovic SD.: Prevalence of dental caries in hospitalized patients with schizophrenia. Vojnosanit Pregl.Vo.73.pp.1106. (2016)

[4] Velasco-Ortega E, Monsalve-Gull L, Ortiz-Garcia I, Jimenez-Guerra A, Lopez-Lopez J, SeguraEgea J,J 2017 Dental caries status of patients with schizophrenia in Seville, Spain: a case control study. BMC Res Notes.Vol.10.pp 2. (2016)

[5] Muench J, Hamer AM.: Adverse effect of antipsychotic medications. American Family Physician Vol.81.pp.617.(2010)

[6] Krunic J, Stojanovic N, Ivkovic N, Stojic D.; Salivary flow rates and decayed, missing, and filled teeth (DMFT) in female patients with schizophrenia on chlorphomazine therapy. Journal of dental sciences Vol.8.pp.419.(2013)

[7] Mos DM.: Saliva secretion disorder in a schizophrenic patient - a problem in dental and psychiatric treatment: a case report. Mos Annals of General Psychiatry.Vol.14.pp 1-2. (2015)

[8] Dyasanoor S, Khader NFA.; Alteration in salivary properties and taste perception in OSMF. Contemp Clin Dent 2016; Vol.7.pp.147. (2016)

[9] Hashimoto Y, Uno J, Miwa T, Kurihara M, Tanifuji H, Tensho M.:Effects of antipsychotic polypharmacy on side-effects and concurrent use of medications in schizophrenic outpatients. Psychiatry and clinical neurosciences Vol.66.pp. 409. (2016) 